\title{
Regulation of Survivin and CDK4 by Epstein-Barr virus encoded latent mem- brane protein 1 in nasopharyngeal carcinoma cell lines
}

\author{
Mi Dan $\mathrm{AI}^{1}$, Li Li $\mathrm{LI}^{1}$, Xiao Rong $\mathrm{ZHAO}^{1}$, Yong $\mathrm{WU}^{1}$, Jian Ping $\mathrm{GONG}^{2}$, Ya $\mathrm{CAO}^{1, *}$ \\ ${ }^{1}$ Cancer Research Institute, Xiangya School of Medicine, Central South University, 110 Xiangya Road, Changsha, Hunan \\ 410078, China \\ ${ }^{2}$ Molecular Medical Center, Tongji Hospital, Tongji Medical University, Wuhan 430030, China
}

\begin{abstract}
Latent membrane protein 1 (LMP1), an important protein encoded by Epstein Barr virus (EBV), has been implied to link with the pathogenesis of nasopharyngeal carcinoma (NPC). Its dual effects of increasing cell proliferation and inhibiting cell apoptosis have been confirmed. In this study, we showed that the expression of Survivin and CDK4 protein in CNE-LMP1, a LMP1 positive NPC epithelial cell line, is higher than in LMP1 negative NPC epithelial cell lineCNE1, and the expression is LMP1 dosage-dependent. Although it was reported that Survivin specifically expressed in cell cycle $\mathrm{G}_{2} / \mathrm{M}$ phase, our studies suggested that LMP1 could promote the expression of Survivin in $\mathrm{G}_{0} / \mathrm{G}_{1}, \mathrm{~S}$ and $\mathrm{G}_{2} /$ M phase. It also showed that Survivin and CDK4 could be accumulated more in the nuclei triggered by LMP1. More interestingly, Survivin and CDK4 could form a protein complex in the nuclei of CNE-LMP1 rather than in that of CNE1, which demonstrated that the interaction between these two proteins could be promoted by LMP1. These results strongly suggested that the role of LMP1 in the regulation of Survivin and CDK4 may also shed some light on the mechanism research of LMP1 in NPC.
\end{abstract}

Keywords: EBV, latent membrane protein 1, cell cycle, $\mathrm{G}_{1} / \mathrm{S}$ check point, Survivin, CDK4.

\section{INTRODUCTION}

Resistance of apoptosis and increase of proliferation are two major molecular traits, which almost exist in all the human cancers. Epstein-Barr virus (EBV) is etiologically associated with several human malignancies such as Burkitt's lymphoma etc, especially nasopharyngeal carcinoma (NPC). EBV encoded latent membrane protein 1 (LMP1) is considered as the major oncogenic protein among the EBV encoded proteins, because it can transform rodent fibroblasts and has tumorigenic in nude mice. LMP1 is involved in multiple biological functions such as cell proliferation, differentiation, transformation, apoptosis. It has been proved that LMP1 can regulate these biological activities through NF- $\mathrm{KB}$, AP-1 and JAK/STAT three major signaling pathways [1-7]. LMP1 could promote the progression of cell cycle by regulating cell cycle regulators, which result in its dual biological effects of promoting

*Correspondence: $\mathrm{Ya} \mathrm{CAO}$

Tel: +86-731-4805448; Fax: +86-731-4470589;

E-mail:ycao98@public.cs.hn.cn cell proliferation and inhibiting apoptosis [3-6].

Survivin, an inhibitor of apoptosis protein (IAP), is absent from most adult tissues, but it is notable for its expression in budding embryo tissues and lots of human cancers. The expression of Survivin is widely involved in apoptosis, proliferation, embryo development, blood vessel growth, and immune regulation as well as tumor metastasis. The role of apoptosis inhibition is closely associated with the poor prognosis and the short survival time of patients. More interestingly, as an apoptosis protein, Survivin possesses $\mathrm{G}_{2} / \mathrm{M}$ phase specific expression [8-10], which is the only member of the IAP family whose expression is known to be regulated through the cell cycle. Our previous studies showed that LMP1 could regulate the expression of Survivin via NF- $\mathrm{kB}$ and AP-1 signaling pathways, which blocked caspase-3 proteolysis activity, and inhibit apoptosis. Our data further suggested the phosphorylation level of $\mathrm{Rb}$ decreased when the expression of Survivin mRNA was inhibited, and the number of S stage cells numbers also decreased [11-12]. These findings hinted that Survivin could play its unusual role in $\mathrm{G}_{1} / \mathrm{S}$ phase under the control of LMP1. 
We have previously confirmed that LMP1 could induce cell cycle $\mathrm{G}_{1} / \mathrm{S}$ checkpoint disorder through upregulating the expression of cyclinD1 and downregulating the expression of p16 [13-14]. Although $\mathrm{G}_{1} / \mathrm{S}$ checkpoint is controlled by many proteins, CDK4 is the core protein among them, and CyclinDI and CKI eventually act on CDK4 to influence the $\mathrm{G}_{1} / \mathrm{S}$ checkpoint. So it is meaningful to study whether LMP1 could play a role in the $\mathrm{G}_{1} / \mathrm{S}$ checkpoint by regulating CDK4. Meanwhile, Suzuki reported that Survivin could promote cell proliferation by competitively interacting with CDK4, over-expression of Survivin could release CDK inhibitors p21 (WAF1/Cip1) and p16 $6^{\mathrm{INK} 4 \mathrm{a}}$ from CDK4. This molecular interaction may play an important role in carcinogenesis and progression of human HCC [15-16]. Therefore, detailed mechanism of LMP1 regulating Survivin in $\mathrm{G}_{1} / \mathrm{S}$ phase need to be further confirmed.

Based on our previous work, we hope focus the present study on the regulation of LMP1 on Survivin and CDK4, so we can gain further insights into the mechanism of LMP1 in increasing cell proliferation and inhibiting cell apoptosis in NPC cells.

\section{MATERIALS AND METHODES}

\section{Cell lines and culture}

CNE1 is a LMP1-negative highly differentiated nasopharyngeal carcinoma cell line. CNE-LMP1 is a stably transfected cell line, established by introducing LMP1 cDNA into the CNE1 cell, in which LMP1 is highly expressed. CNE1 and CNE-LMP1 were maintained in RPMI1640 (GIBCO BRL) medium supplemented with $10 \%$ heatinactivated fetal calf serum. Tet-on-LMP1-HNE2 is an established cell line using a newly developed Tet-on gene expression system in which LMP1 is highly effectively expressed in a dosage-dependent manner. Tet-on-LMP1 HNE2 cells were cultured in RPMI 1640 medium with $100 \mathrm{mg} / \mathrm{L}$ of G418 and $50 \mathrm{mg} / \mathrm{L}$ of hygromycin, supplemented with $10 \%$ fetal calf serum. To induce the LMP 1 expression, Tet-on-LMP1 HNE2 cells were treated with doxcyclin at the following dosages: $0,0.006,0.06$, and $0.6 \mu \mathrm{g} / \mathrm{ml}$ [17]. All the cells grow at $37^{\circ} \mathrm{C}$ in a humidified atmosphere of $5 \% \mathrm{CO} 2$ and $95 \%$ air.

\section{Antibodies and reagents}

LMP1 (CS 1-4) is a monoclonal antibody from mice against human LMP1 protein (from DAKO); $\alpha$-tubulin (B-7) (SC-5286) is a monoclonal antibody from mice against human á-tubulin protein (from Santa Cruz, USA); nucleolin (MS-3) (SC-8031) is a mouse monoclonal IgG1 antibody raised against a recombinant protein corresponding to amino acids 1-706 representing full length nucleolin of human origin (from Santa Cruz, USA); Survivin (C-19) (SC-8807) is a polyclonal antibody from goat against human Survivin protein Cterminal (from Santa Cruz, USA); CDK4 (C-22)(SC-260) is a polyclonal antibody from rabbit against human CDK4 protein $\mathrm{C}$ terminal (from Santa Cruz, USA); anti-rabbit IgG labeled with FITC (IF0020) is from Sino-American Biotechnology Co.; anti-mouse IgG labeled with Cy3 (C2181) is from Sigma; anti-Goat IgG, H\&L (FITC) (11904-28A) and anti-rabbit IgG, H\&L (Rhodamine) are from the Unite State Biological Co. BCA Assay Reagent, Supersignal Chemi- luminescence System (ECL) and NE-PER Nuclear and Cytoplasmic Extraction Reagents are from Pierce Chemical Co.

\section{Protein extraction}

Cells were collected and washed with ice-cold PBS for 3 times, added lysis buffer ( $50 \mathrm{mM} / \mathrm{L}$ Tris-Cl, $1 \mathrm{mM} / \mathrm{L}$ EDTA, $20 \mathrm{~g} / \mathrm{L}$ SDS, $5 \mathrm{mM} / \mathrm{L} \mathrm{DTT}$, and $10 \mathrm{mM} / \mathrm{L} \mathrm{PMSF}$ ) and laid on ice for $30 \mathrm{~min}$, boiled for $10 \mathrm{~min}$ and then treated with ultrasonication for $30 \mathrm{~s}$. All procedures were carried out at $4^{\circ} \mathrm{C}$. Proteins were collected by the centrifugation at $10,000 \times \mathrm{g}$ for $10 \mathrm{~min}$. Protein concentrations were determined using BCA protein assay reagent (Pierce Chemical Co. Rockford, IL) with bovine serum albumin as a standard.

\section{Preparation of fractionated proteins}

Cells were lysed and extracted using the NE-PER Nuclear and Cytoplasmic Extraction Reagents Kit (Pierce Chemical Co. Rockford). The fractionated proteins were assayed by Western blot.

\section{Western blot analysis}

Sample proteins separated by SDS-PAGE were transferred to nitrocellulose membrane. The membranes were blocked with PBS containing $5 \%(\mathrm{w} / \mathrm{v})$ skim milk at $4^{\circ} \mathrm{C}$ for $2 \mathrm{~h}$, washed with a mixture of PBS and $0.05 \%$ Tween-20, and then incubated overnight with each antibody diluted with PBS. After washed with Tween-PBS, the membrane was incubated with diluted biotinylated $\mathrm{IgG}$, washed with Tween-PBS, and then incubated with avidin -HRP at room temperature for $2 \mathrm{~h}$, the membranes were washed with Tween-PBS and then developed with the ECL system.

\section{Immunofluorescence analysis}

Cellular localization of proteins was investigated by immunofluorescence. CNE1 cells and CNE-LMP1 cells were washed with cold PBS and fixed with cold $3.7 \%$ polyformaldehyde for 30 min. Primary antibody was diluted 1:200 with PBS (Phosphate Buffered Saline) and incubated with the cells at $4^{\circ} \mathrm{C}$ overnight. Fluorescein-labeled IgG was diluted 1:1000 with PBS, incubated with the cells to bind with the primary antibody. Cellular localization of proteins was observed under fluorescence microscope or Laser Scanning Confocal Microscopy.

\section{Immunoprecipitation analysis}

We incubated $100 \mathrm{mg}$ proteins from each cell lysate with protein A-sepharose at $4^{\circ} \mathrm{C}$ for $30 \mathrm{~min}$ for pre-clear. The supernatant was collected by centrifugation $(1,000 \times \mathrm{g}, 5 \mathrm{~min})$, then incubated with Survivin or CDK4 antibody at $4^{\circ} \mathrm{C}$ overnight. The next day, protein A-sepharose was added into the mixture and incubated for $30 \mathrm{~min}$. The immunoprecipitates were washed, electrophoresed, and analyzed by Western blot with antibodies against Survivin or CDK4.

\section{Flowcytometry cell cycle analysis and cell sorting}

Cells were collected, rinsed with PBS and suspended in $75 \%$ ethanol at $-20^{\circ} \mathrm{C}$ overnight. Fixed cells were centrifuged and washed with PBS twice. To detect the DNA content, cells were incubated in the dark with $50 \mu \mathrm{g} / \mathrm{ml}$ of PI and $0.1 \%$ of RNase A in $400 \mu \mathrm{l} \mathrm{PBS}$ at $25^{\circ} \mathrm{C}$ for $30 \mathrm{~min}$. Stained cells were assayed on FACSort (Becton Dickinson). The percentage of cell cycle phases was analyzed using the Cell Quest software program. In cell sorting, cells were incubated in the dark with $50 \mu \mathrm{g} / \mathrm{ml}$ of PI and $0.1 \%$ of RNase A in $400 \mu \mathrm{l}$ PBS 
A

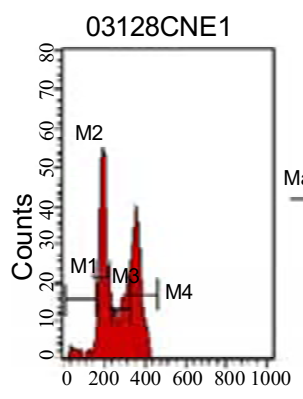

FL2-A

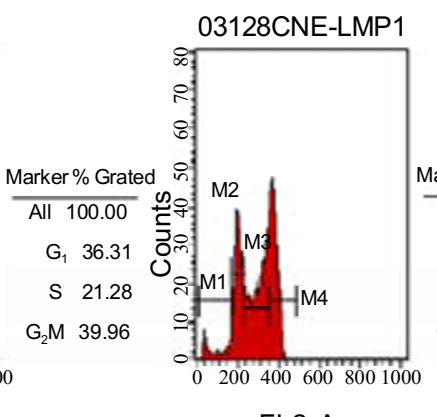

FL2-A
B

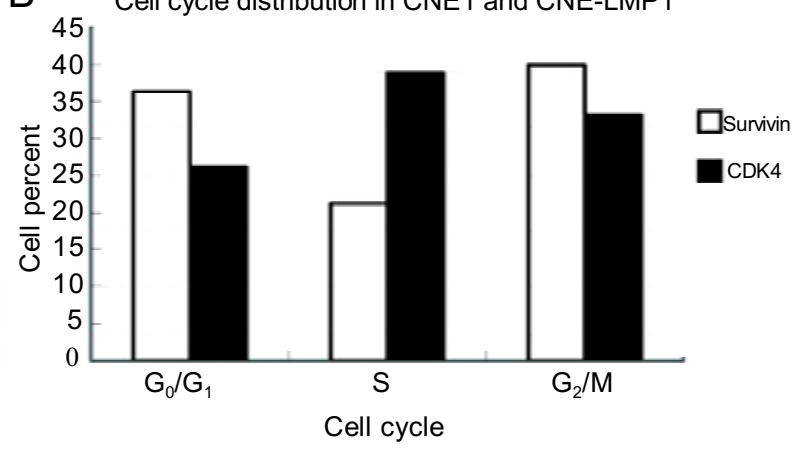

Fig. 1 Flow Cytometry analysis of CNE1 and CNE-LMP1 cell cycle distribution. (A) $G_{1}, S$ and $G_{2} / M$ percentage of CNE1 and CNE-LMP1. The same amount cells were seeded and cultured for $24 \mathrm{~h}$, then analyzed the cell cycle through Flow Cytometry. (B) The column diagram of the value of (A).

A

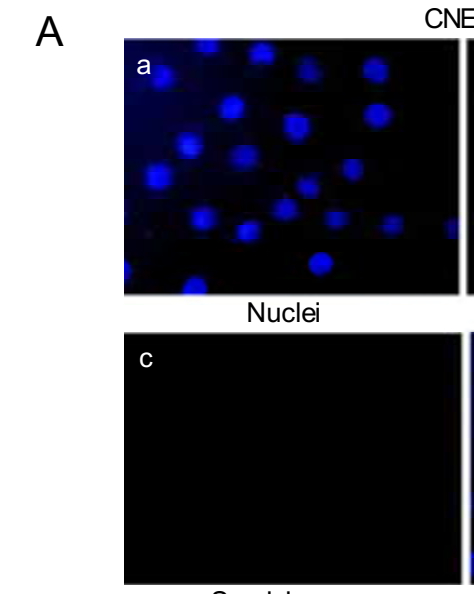

CNE1

C

$$
\text { Survivin }
$$
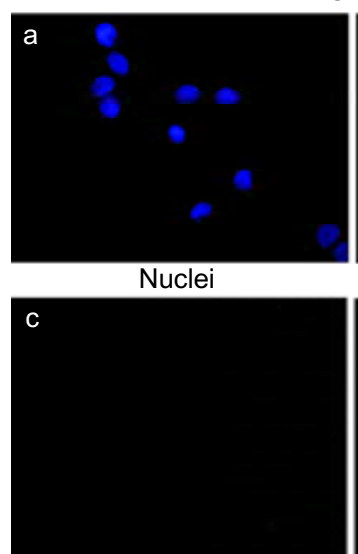

CDK4

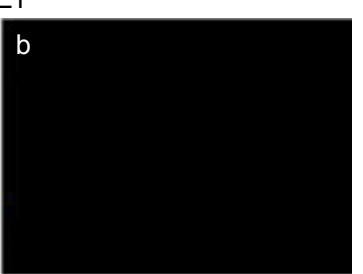

LMP1

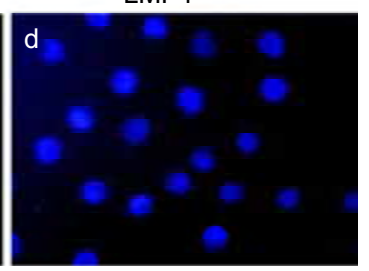

Merge

CNE1

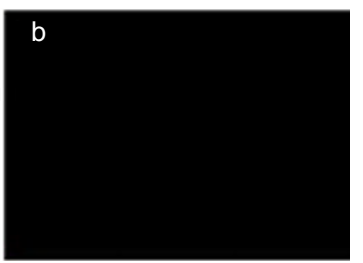

LMP1

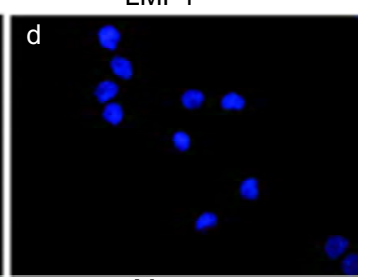

Merge
B

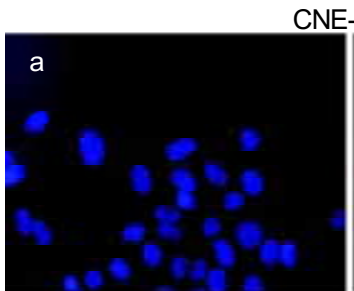

Nuclei

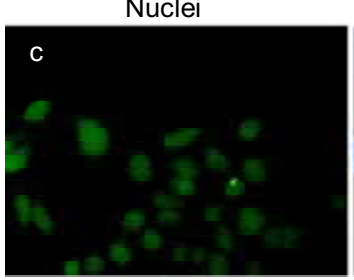

Survivin

D

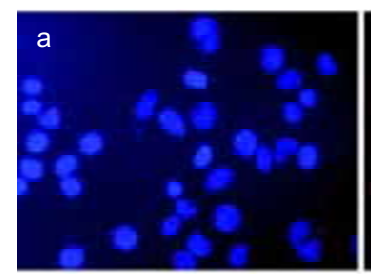

Nuclei

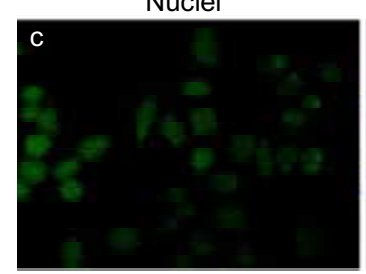

CDK4
CNE-LMP1

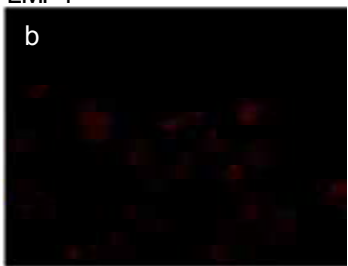

LMP1

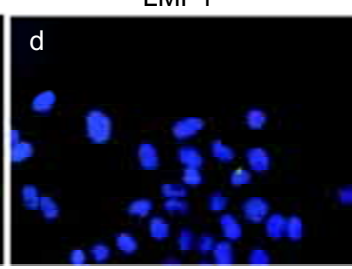

Merge

NEE-LMP1
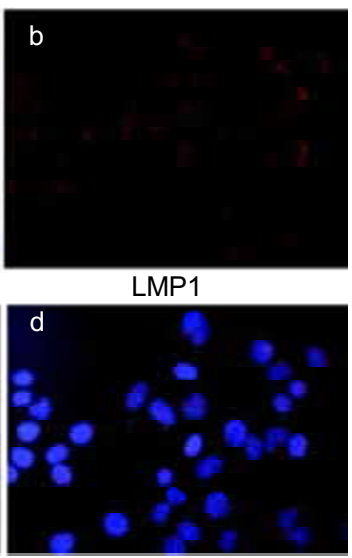

Merge

Fig. 2 Localization and co-localization of LMP1 and CDK4, LMP1 and Survivin detected by immunofluorescence. (A) (B) LMP1 could promote Survivin expression and nuclear accumulation. (C) (D)LMP1 could promote CDK4 expression and nuclear accumulation. The nuclei were stained with Hochest33258 (blue). After the staining, all cells were observed under Fluorescence Microscope 
at $25^{\circ} \mathrm{C}$ for $30 \mathrm{~min}$. Stained cells were sorted into $\mathrm{G}_{0} / \mathrm{G}_{1}, \mathrm{~S}$, and $\mathrm{G}_{2} / \mathrm{M}$ phases respectively according to their DNA contents on FACSort (Becton Dickinson) and the cells of each section were collected and the proteins were prepared for Western blot analysis.

\section{RESULTS}

\section{Acceleration of cell cycle $G_{1}-S$ phase transition in $\mathrm{CNE}$ -} LMP1

Through flow cytometry (FCM) analysis, we observed that CNE-LMP1 cells had higher $\mathrm{S}$ phase proportion than CNE1 cells, and the $\mathrm{G}_{0} / \mathrm{G}_{1}$ phase proportion of CNE-LMP1 was obviously lower than that of CNE1 (Fig. 1), which suggested that $G_{1}-S$ phase transition had been accelerated under the regulation of LMP1.

\section{Promotion of Survivin and CDK4 expression by LMP1}

Based on the regulation of LMP1 on cell cycle $\mathrm{G}_{1}-\mathrm{S}$ phase transition, we detected the expression of Survivin and CDK4 in CNE1 and CNE-LMP1. Double staining immunofluorescence indicated that CNE-LMP1 had obviously higher expression of Survivin and CDK4 than CNE1 had, and LMP1 expression was homogeneous in CNE-LMP1 (Fig. 2). Then Western blot was also performed to detect the expression of Survivin and CDK4. These data approved
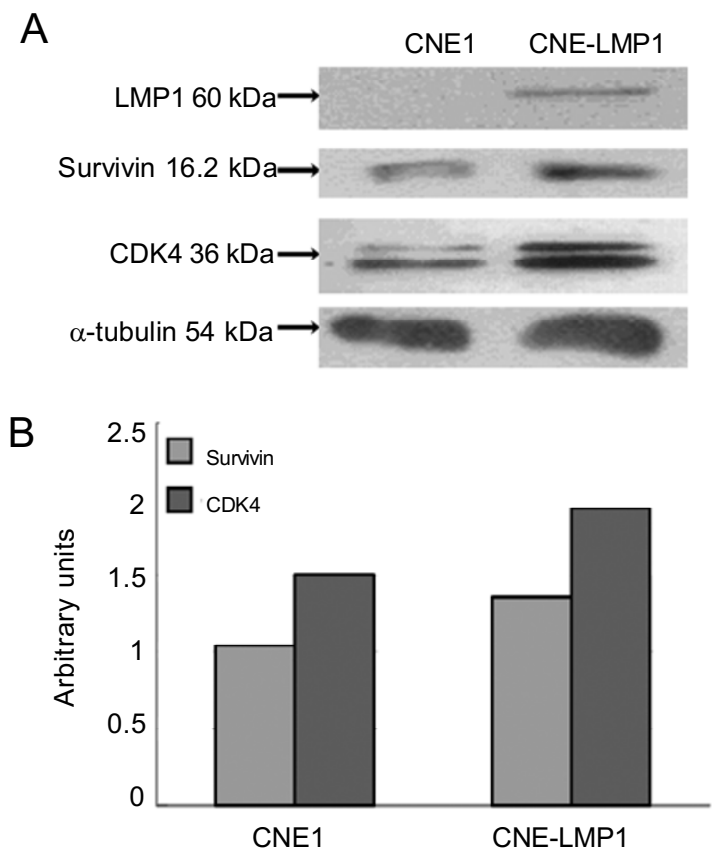

Fig. 3 Survivin and CDK4 expression in CNE1 and CNE-LMP1 (A) LMP1 could upregulate the expression of Survivin and CDK4. (B) The column diagram demonstrated the density value of Survivin/ tubulin and CDK4/tubulin for correction after the results of (A) being scanned on VDS.
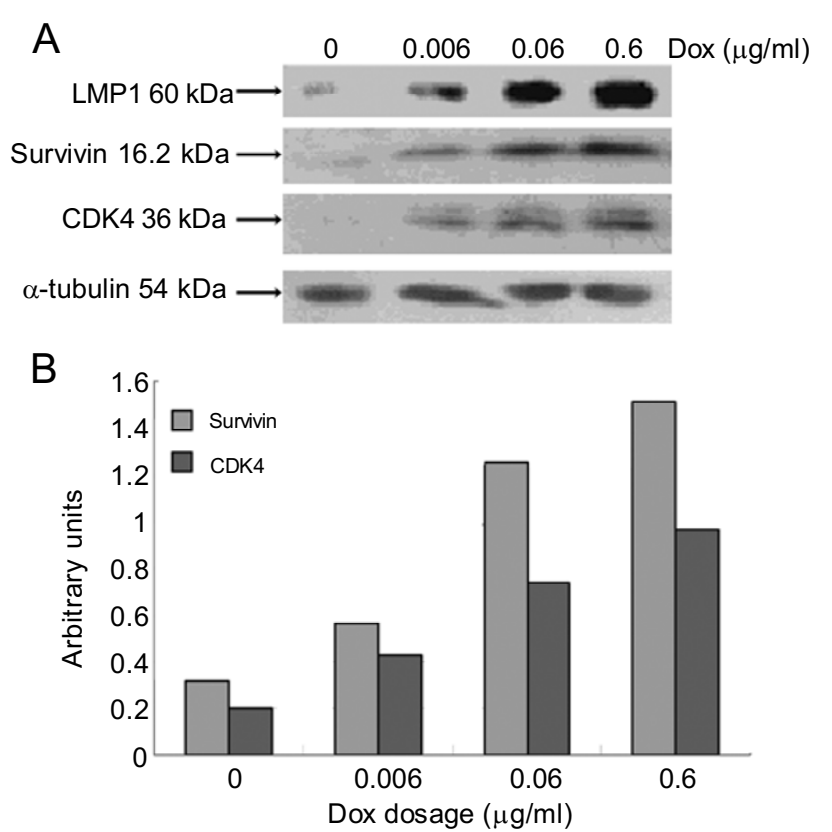

Fig. 4 Survivin and CDK4 protein expression triggered by LMP1 in a dosage-dependent manner. (A) Western blot of LMP1, Survivin and CDK4 in Tet-on- LMP1- HNE2 cells induced by 0, 0.006, 0.06, and $0.6 \mathrm{ug} / \mathrm{ml}$ DOX. (B) The column diagram demonstrated the density value of Survivin/tubulin and CDK4/tubulin for correction after the results of (A) being scanned on VDS.

the results of immunofluorescence analysis. It demonstrated that Survivin and CDK4 expression was higher in CNELMP1 cell than in CNE1 cell, and LMP1 was exclusively detected in CNE-LMP1 (Fig. 3). Using Tet-on-LMP1 HNE2 NPC cell line in which LMP1 expressed in a dosage-dependent manner by doxycycline (DOX) inducing, we further confirmed that Survivin and CDK4 protein expression could be regulated by LMP1 in a dosage-dependent manner, which increased gradually with the LMP1 expression, when the cells were treated with $0,0.006,0.06$, and $0.6 \mu \mathrm{g} / \mathrm{ml}$ DOX (Fig. 4).

\section{Influence of cell cycle dependent expression of Survivin by LMP1}

It was reported that Survivin had cell cycle specific expression. In order to determine the influence of LMP1 on Survivin expression in different cell cycle phases, we used flow cytometry to sort CNE1 cells and CNE-LMP1 cells into 3 different sections: $G_{0} / G_{1}, S$, and $G_{2} / M$, extracted the protein of each section to assay Survivin expression through Western blot. The validity of sorting was confirmed through post-sorting Western blot of cyclin D1, cyclin $\mathrm{E}$ and CDK2, which were cell cycle related proteins and had cell cycle dependent expression. Cyclin D1 had specific expression in $\mathrm{G}_{0} / \mathrm{G}_{1}$ phase, and cyclin $\mathrm{E}$ and 
A

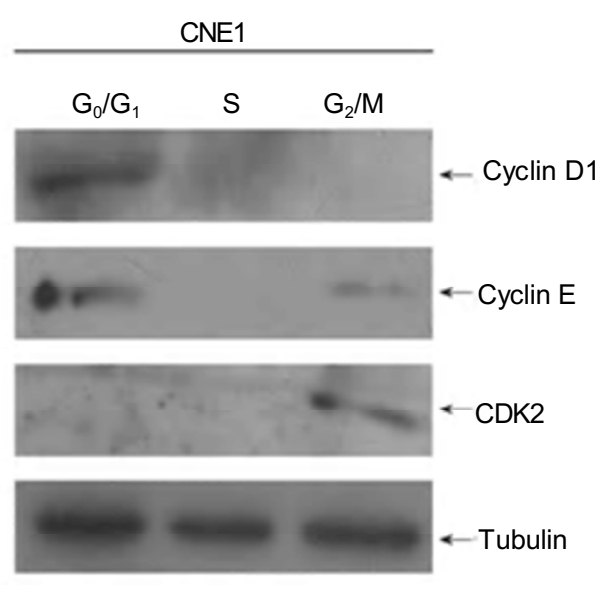

B

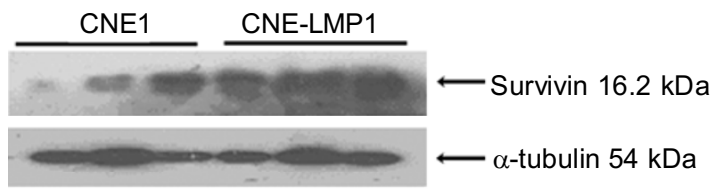

C

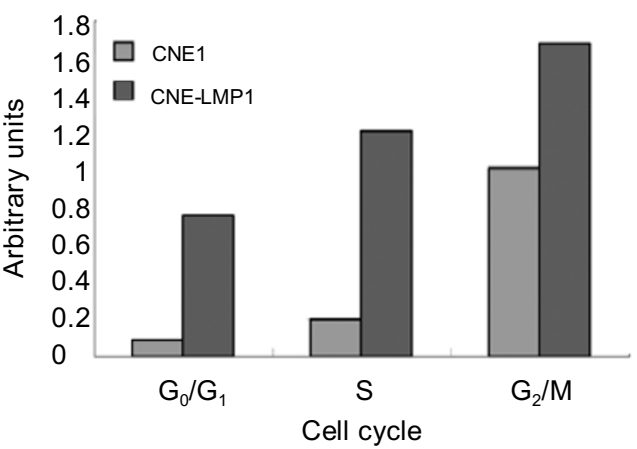

Fig. 5 Survivin expression in different cell cycle phases. The cells were sorted on Flow Cytometry according to $G_{0} / G_{1}, S$, and $G_{2} / M$ phases and the protein of each phase was prepared and loaded on the SDS-Page. (A) cylin D1 was expressed in $\mathrm{G}_{0} / \mathrm{G}_{1}$ phase, cyclin E was expressed in $G_{0} / G_{1}$ and $G_{2} / M$ phase, and CDK2 was expressed in $G_{2} / M$ phase. (B) Western blot of Survivin in $G_{0} / G_{1}, S$, and $\mathrm{G}_{2} / \mathrm{M}$ phases of CNE1 cells and CNE-LMP1 cells after sorting. In CNE1 Survivin is mainly in $\mathrm{G}_{2} / \mathrm{M}$ phase, but in CNE-LMP 1 it is in all the three phase. Tubulin expression was also detected as a control. For correction, the column diagram demonstrated the density value of Survivin/tubulin (C).

CDK2 had specific expression in $\mathrm{G}_{2} / \mathrm{M}$ phase. Our result indicated that the sorted cells were indeed in the three different phases of the cell cycle (Fig. 5 A). Post-sorting Western blot of Survivin showed that Survivin expression was mainly in $\mathrm{G}_{2} / \mathrm{M}$ phase, and was weak in $\mathrm{G}_{0} / \mathrm{G}_{1}$ phase, clear in $\mathrm{S}$ phase in CNE1. However, in CNE-LMP1, Survivin expression was very clear in each of the 3 phases, $\mathrm{G}_{0} / \mathrm{G}_{1}, \mathrm{~S}$, and $\mathrm{G}_{2} / \mathrm{M}$ (Fig. 5 B).

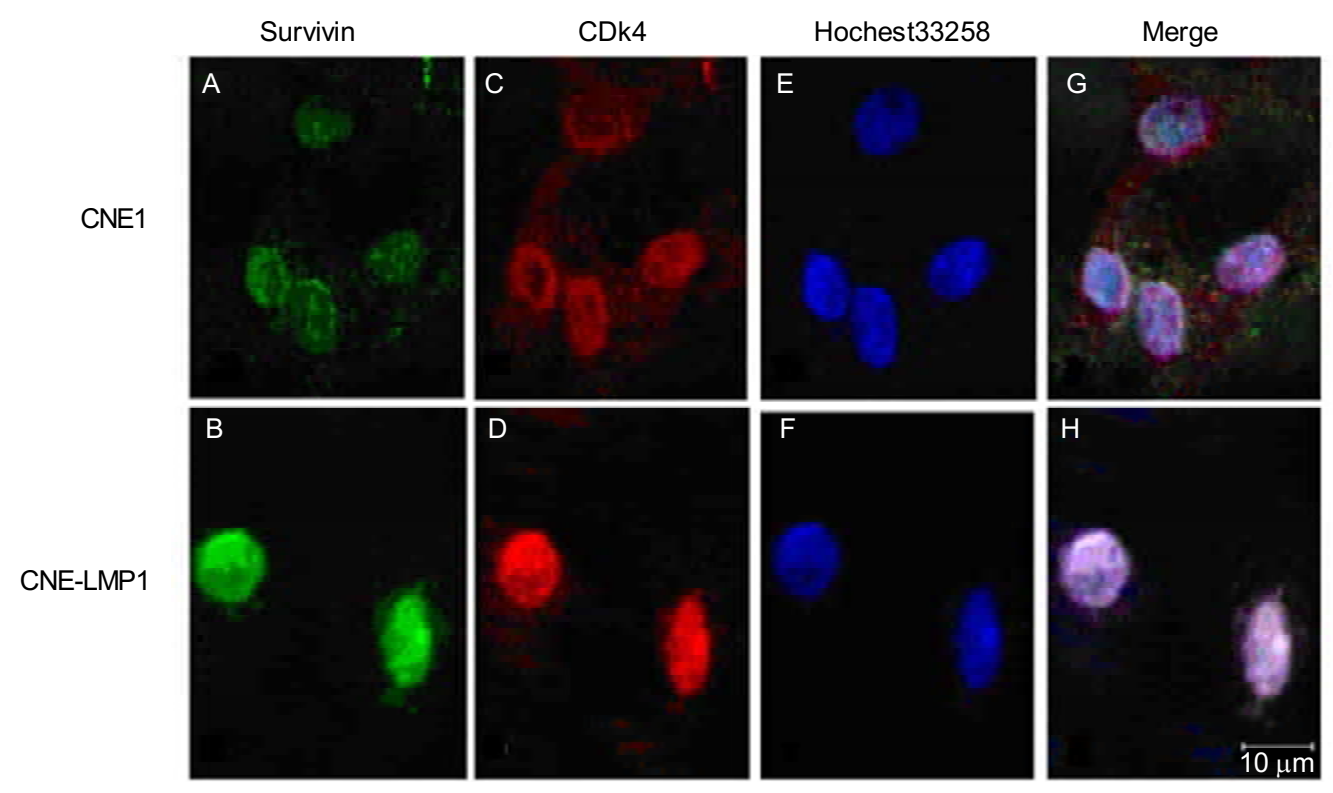

Fig. 6 Localization and co-localization of Survivin and CDK4 detected by immunofluorescence. $(\mathbf{A}, \mathbf{C})$ In CNE1 cell line, Survivin and CDK4 were mainly expressed in cytoplasm. (B, D) In CNE-LMP1 cell line, Survivin and CDK4 were mainly expressed in nuclei. (E, F) The nuclei were stained with Hochest33258 (blue). After the staining, all cells were observed under Laser Scanning Confocal Microscopy. $(\mathbf{G}, \mathbf{H})$ The overlap of nuclei, Survivin and CDK4 was showed in CNE1 cells and CNE-LMP1 cells. 


\section{Promotion of nuclear accumulation of Survivin and CDK4 by LMP1}

Cellular localization of Survivin and CDK4 was meaningful for their functions. In this study immunofluorescence analysis was performed to detect the localization of Survivin and CDK4. The results indicated that Survivin and CDK4 mainly located in the cytoplasm and nuclear membrane in CNE1 cell line, but in CNE-LMP1, they were mostly located in the nuclei. It was suggested that LMP1 might promote accumulation of Survivin and CDK4 in the nuclei (Fig. 6). From Fig. 6G and 6H, we could see that CDK4 and Survivin were merged as white in the nuclei of CNE-LMP1 cell, but in CNE1 nuclei, they did not appear overlapping fluorescence. These results demonstrated that LMP1 might be involved in promoting co-location of Survivin and CDK4 in nuclei. To further confirm the above assumption, Western blot analysis of cellular fractionations was also performed to determine the localization of Survivin and CDK4. The data showed that both Survivin and CDK4 were detected in the nuclei and cytoplasm. But in the nuclei the expression of Survivin and CDK4 was higher in CNE-LMP1 than that in CNE1, especially for Survivin expression. Furthermore, both Survivin and CDK4 expression in the cytoplasm of CNE-LMP1 was a little less than that in CNE1 (Fig. 7). So these data were further confirmed the results of immunofluorescence analysis, which indicated that LMP1 could promote the nuclear accumulation of Survivin and CDK4.

\section{Initiation of Survivin/ CDK4 complex formation in the nuclei by LMP1}

The co-localization of Survivin and CDK4 in the nuclei of CNE-LMP1 suggested the possible interaction between

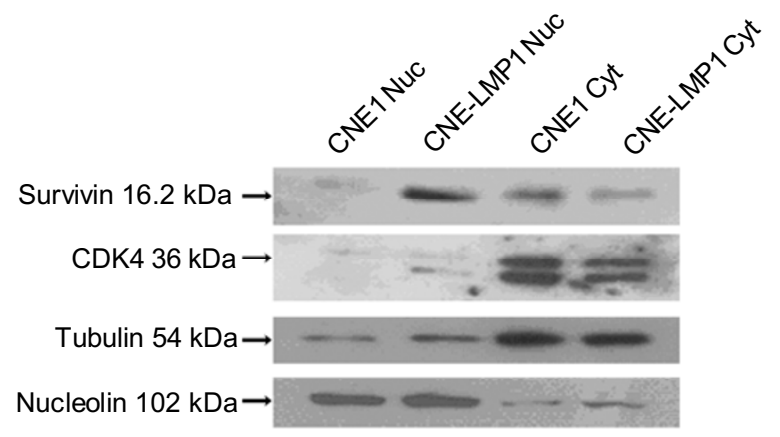

Fig. 7 Survivin and CDK4 expression in different cellular fractions. Nuclear (Nuc.) protein and Cytoplasmic (Cyt.) proteins of CNE1 and CNE-LMP1 cells were separated and both Survivin and CDK4 were detected in nuclear and cytoplasmic protein by Western blot. Tubulin as a cytoplasmic protein marker and Nucleolin as nuclear protein marker were used for a loading control [35]

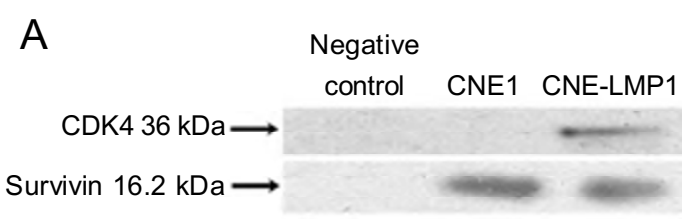

IP: Survivin; IB CDK4, Survivin

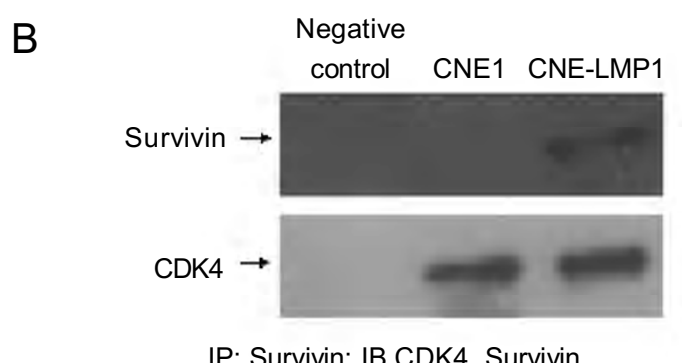

Fig. 8 Immunoprecipitation of Survivin and CDK4. (A) The Survivin protein complexes in CNE1 and CNE-LMP1 cell lysates were precipitated using Survivin antibody-conjugated with protein Asepharose. The negative control was the CNE-LMP1 cell lysates precipitated only with protein A-sepharose. The immunoprecipitates were separated by SDS-PAGE and detected with both CDK4 and Survivin antibodies. Survivin detection in this experiment was performed to evaluate the amount of Survivin in immunoprecipitates. (B) The CDK4 protein complexes in CNE1 and CNE-LMP1 cell lysates were precipitated using CDK4 antibody-conjugated with protein A-sepharose. The negative control was the CNE-LMP1 cell lysates precipitated only with protein A-sepharose. The immunoprecipitates were separated by SDS-PAGE and detected with both CDK4 and Survivin antibodies. CDK4 detection in this experiment was performed to evaluate the amount of CDK4 in immunoprecipitates.

Survivin and CDK4 triggered by LMP1. In the following study, co-immunoprecipitation was used to provide the direct evidence for this assumption. In this experiment, Survivin and CDK4 protein complexes were precipitated from CNE1 and CNE-LMP1 cell lysates respectively, and both CDK4 and Survivin were detected in these immunoprecipitates after being separated by Western blot. As shown in Fig. 8, CDK4 detected in Survivin complexes (Fig. 8A) and Survivin detected in CDK4 complexes (Fig. 8B) were only found in CNE-LMP1, neither in CNE1 nor in the negative control. The results indicated that Survivin/ CDK 4 complex only existed in CNE-LMP1, which suggested LMP1 was involved in inducing the formation of Survivin/CDK4 complex in the nuclei.

\section{DISCUSSION}

Uncontrolled proliferation is a fundamental feature of cancer cells, many cell cycle regulators that control the correct process of cell cycle are altered in tumors. In fact, 
most of the cancer cells show the $G_{1} / S$ check point dysfunction. Our study has confirmed that EBV LMP1 could cause the $\mathrm{G}_{1} / \mathrm{S}$ check point disorder and accelerate $\mathrm{G}_{1}-\mathrm{S}$ transition in NPC cells $[15,16] . \mathrm{G}_{1} / \mathrm{S}$ check point is a critical restriction point co-regulated by Cyclin D and CDK4. Only when CyclinD (mostly CyclinD1) forms the active kinase complex with CDK4, they can phosphorylate $\mathrm{Rb}$, then release the transcription factor E2F and initiate transcription of a series of genes linked with $\mathrm{S}$ phase progress, eventually the cells complete $\mathrm{G}_{1}-\mathrm{S}$ transition and start the cell cycle process. Our previous study had confirmed that CyclinD1 and p1 6 could be regulated by LMP1. Based on these, we further examined the regulation of LMP1 on CDK4. Our study found that LMP1 could increase CDK4 expression and nuclear accumulation, which may acts as a complementary and perhaps be more important mechanism of LMP 1 regulating $G_{1} / S$ check point. As an important kinase, CDK4 has the main function to start DNA replication and induce cell mitosis. It is usually thought that CDK4 expressed stably in cells, but recently more and more reports confirmed its over-expression in tumors. Some experiments showed that over-expression of CDK4 was closely associated with the acceleration of tumor cell $\mathrm{G}_{1}-\mathrm{S}$ transition and cell malign-proliferation [18-31]. Only when CDK 4 moves from the cytoplasm to the nuclei, it can play its roles in the cell cycle regulation and cell proliferation promotion. Nuclear translocation of CDK4 induced by LMP1 may be an essential mechanism for LMP1 promoting cell proliferation.

It is reported that Survivin has specific expression during $\mathrm{G}_{2} / \mathrm{M}$ phase of the cell cycle, followed by rapid decline of both mRNA and protein levels at the $\mathrm{G}_{1}$ phase, and the protein has a half-life about $30 \mathrm{~min}$ [12]. Our study revealed that the expression of Survivin in $\mathrm{G}_{2} / \mathrm{M}$ phase was mostly higher among 3 phases, and $\mathrm{S}$ phase took the second place, then the $G_{0} / G_{1}$ phase, which was consistent with the previous study [37-38]. Although LMP1 increase Survivin expression in all the 3 phases, it has more obviously effect on regulating the expression of Survivin in $\mathrm{G}_{0} / \mathrm{G}_{1}$ and $\mathrm{S}$ phase, which suggested that Survivin may play unusual role in $G_{1} / S$ phase. Recently it was reported that Survivin was degraded through ubiquitin-proteasome proteolytic pathway at $\mathrm{G}_{1}$ phase. So whether LMP1 regulate Survivin expression through increasing protein translation or extending its half time in $G_{1}$ phase is obscure [10].

Survivin is a cytoplasmic protein, and the nuclear localization is required for its function in the proliferation and apoptosis regulation [32-34]. In the present study, we showed that LMP1 could promote Survivin to accumulate in the nuclei and bind with CDK4. The role of these competitive interaction of Survivin with CDK4 is that Survivin could release CDK inhibitor p21 (WAF1/Cip1) and p16 $6^{\mathrm{INK} 4 \mathrm{a}}$, then assist $\mathrm{CDK} 4$ to bind $\mathrm{Rb}$ and trigger gene expression related to $S$ phase progress. Additionally, Survivin initiates procaspase3/p21 complex formation as a result of interaction with CDK4 to resist Fas-mediated cell death [1112]. Some studies reported that Survivin was a nuclear shuttling protein, which was actively exported from the nuclei via the CRM1-dependent pathway [39]. So the mechanism of LMP1 promoting Survivin nuclear accumulation is not clear. Although detail study is needed, our study provided an important evidence for the regulation of LMP1 on Survivin and CDK4, which may be another mechanism of LMP1 in promoting the cell cycle $\mathrm{G}_{1}-\mathrm{S}$ transition.

\section{ACKNOWLEDGEMENTS}

The authors would like to thank Dr Qiao WU (Key Laboratory of the Ministry of Education for Cell Biology and Tumor Cell Engineering, Xiamen University, China) and Dr Zhi Min YUAN (Department of Cancer Cell Biology, Harvard School of Public Health, USA) for their helpful discussions.

This work was supported by National Nature Science Foundation for Distinguished Young Scholar of China (No. 39525022), National Basic Research Program (No. 2004CB518703), and National Nature Science Foundation of China (No. 30570085).

Received, Sep 12, 2005;

Revised, Sep 26, 2005;

Accepted, Oct 15,2005

\section{REFERENCES}

1 Eudoxia $\mathrm{H}$, George M. Cellular signaling pathway engaged by the Epstein-barr virus transforming protein LMP1. Front Biosci 2002; 7:319-29.

2 Huen DS, Henderson SA, Croom-Carter D, et al. The EpsteinBarr virus latent membrane protein-1(LMP1) mediates activation of NF-êB and cell surface phenotype via two effector regions in its carboxy-terminal cytoplasmic domain. Oncogene 1995; 10:549-60.

3 Mitchell T, Sugden B. Stimulation of NF-kappa B- mediated transcription by mutant derivatives of the latent membrane protein of Epstein-Barr virus. J virol 1995; 69:2968-76.

4 Kieser A, Kilger EO, Gires O, et al. Epstein-Barr virus latent membrane protein-1 triggers AP-1 activity via the c-Jun N terminal kinase cascade. EMBO J 1997; 16:6478-85.

5 Luo FJ, Hu Z, Deng XY, et al. Epstein-Barr virus LMP-1 activated AP-1 mediated by JNK in Nasopharyngeal cell line. Zhongguo Sheng Wu Hua Xue Yu Fen Zi Sheng Wu Xue Bao 2001; 17:381-5.

6 Gires O, Kohlhuber F, Kilger E, et al. Latent membrane protein 1 of Epstein-Barr virus interacts with JAK3 and activates STAT protein. EMBO J 1999; 18:3064-73. 
7 Tan YN, Tao YG, Song X, et al. Expression of JAK3 in Nasopharyngeal Carcinoma Cell Line Associated With STAT Activation Regulate by EB Virus Encoded Protein LMP1. Sheng Wu Hua Xue Yu Sheng Wu Wu Li Jin Zhan 2003; 30:560-5.

8 Li F, Ambrosini G, Chu EY, et al. Control of apoptosis and mitotic spindle checkpoint by Survivin. Nature 1998; 396:580-4.

9 Li F, Altieri DC. The cancer antiapoptosis mouse Survivin gene: characterization of locus and transcriptional requirements of basal and cell cycle-dependent expression. Cancer Res 1999; 59:3143-51.

10 Zhao J, Tenev T, Martins LM, et al. The ubiquitin-proreasome pathway regulates survivin degradation in a cell cycle-dependent manner. J Cell Sci 2000; 113:4363-7.

11 Tang FQ, Cao Y. Epstein-Barr virus LMP1 triggers the expression of inhibitor of apoptosis protein Survivin via NFêB and AP1 signaling pathway in nasopharyngeal carcinoma. Exp Oncol 2003; 25:28-32.

12 Tang FQ, Gu HH, Hu Z, et al. EB virus latent membrane protein 1 initiates cells proliferation and inhibits apoptosis via Survivin triggering signal-Pathway. Zhongguo Sheng Wu Hua Xue Yu Fen Zi Sheng Wu Xue Bao 2003; 19:646-52.

13 Zhao XR, Wang CX, Luo FJ, et al. The Epstein-Barr Virus Encoded Latent Membrane Protein 1(EBV-LMP1)Activates Expression of CyclinD1. Sheng Wu Hua Xue Yu Sheng Wu Wu Li Jin Zhan 2001; 28:704-10.

14 Song X, Ai MD, Chen XX, et al. Regulation of c-Jun/JunB heterodimers mediated by Epstein-Barr virus encoded latent membrane protein 1 on p16. Chin Sci Bull 2004; 49: 676-83.

15 Suzuki A, Ito T, Kawano H, et al. Survivin initiates procaspase3/ P21 complex formation as a result of interaction with CDK4 to resist Fas-mediated cell death. Oncogene 2000; 19:1346-53.

16 Suzuki A, Hayashida M, Ito T, et al. Survivin initiates cell cycle entry by the competitive interaction with Cdk4/p16(INK4a) and Cdk2/cyclin E complex activation. Oncogene 2000; 19:322534.

17 Liao W, Yi H, Li XY, et al. Doxycycline dependent expression of EBV latent membrane protein 1 with Tet regulating system in Nasopharygeal Carcinomacell line. Sheng Wu Hua Xue Yu Sheng Wu Wu Li Xue Bao 1999; 31:309-12.

18 Skomedal H, Kristensen GB, Lie AK, et al. Aberrant expression of the cell cycle associated proteins TP53, MDM2, p21, p27, CDK4, cyclin D1, RB, and EGFR in cervical carcinomas. Gynecol Oncol 1999; 73:223-8.

19 Chen Q, Luo G, Li B, et al. Expression of p16 and CDK4 in oral premalignant lesions and oral squamous cell carcinomas: a semiquantitative immunohistochemical study. J Oral Pathol Med 1999; 28:158-64.

20 Wunder JS, Eppert K, Burrow SR, et al. Co-amplification and overexpression of CDK4, SAS and MDM2 occurs frequently in human parosteal osteosarcomas. Oncogene 1999; 18:783-8.

21 Benassi MS, Molendini L, Gamberi G, et al. Altered G1 phase regulation in osteosarcoma. Int J Cancer 1997; 74:518-22.

22 Maelandsmo GM, Berner JM, Florenes VA, et al. Homozygous deletion frequency and expression levels of the CDKN2 gene in human sarcomas-relationship to amplification and mRNA levels of CDK4 and CCND1. Br J Cancer 1995; 72:393-8.

23 An HX, Beckmann MW, Reifenberger G, et al. Gene amplification and overexpression of CDK4 in sporadic breast carcinomas is associated with high tumor cell proliferation. Am J Pathol
1999; 154:113-8.

24 Yao J, Pollock RE, Lang A, et al. Infrequent mutation of the p16/ MTS1 gene and overexpression of cyclin-dependent kinase 4 in human primary soft-tissue sarcoma. Clin Cancer Res 1998; 4: 1065-70.

25 Rollbrocker B, Waha A, Louis DN, et al. Amplification of the cyclin-dependent kinase 4 (CDK4) gene is associated with high cdk4 protein levels in glioblastoma multiforme. Acta Neuropathol (Berl) 1996; 92:70-4.

26 Kitahara K, Yasui W, Yokozaki H, et al. Expression of cyclin D1, CDK4 and p27KIP1 is associated with the p16MTS1 gene status in human esophageal carcinoma cell lines. J Exp Ther Oncol 1996; 1:7-12.

27 Zhang T, Nanney LB, Luongo C, et al. Concurrent overexpression of cyclin D1 and cyclin-dependent kinase $4(\mathrm{Cdk} 4)$ in intestinal adenomas from multiple intestinal neoplasia (Min) mice and human familial adenomatous polyposis patients. Cancer Res 1997; 57:169-75.

28 Maelandsmo GM, Florenes VA, Hovig E, et al. Involvement of the $\mathrm{pRb} / \mathrm{p} 16 / \mathrm{cdk} 4 /$ cyclin D1 pathway in the tumorigenesis of sporadic malignant melanomas. Br J Cancer 1996; 73:909-16.

29 Qiu C, Shan L, Yu M, et al. Deregulation of the cyclin D1/Cdk4 retinoblastoma pathway in rat mammary gland carcinomas induced by the food-derived carcinogen 2-amino-1-methyl-6phenylimidazo [4,5-b] pyridine. Cancer Res 2003; 63:5674-8.

30 Izawa H, Yamamoto H, Ikeda M, et al. Analysis of cyclin D1 and CDK expression in colonic polyps containing neoplastic foci: a study of proteins extracted from paraffin sections. Oncol Rep 2002; 9:1313-8.

$31 \mathrm{Kim} \mathrm{H,} \mathrm{Ham} \mathrm{EK,} \mathrm{Kim} \mathrm{YI,} \mathrm{et} \mathrm{al.} \mathrm{Overexpression} \mathrm{of} \mathrm{cyclin} \mathrm{D1} \mathrm{and}$ cdk4 in tumorigenesis of sporadic hepatoblastomas. Cancer Lett 1998; 131:177-83.

32 Martinez A, Bellosillo B, Bosch F, et al. Nuclear survivin expression in mantle cell lymphoma is associated with cell proliferation and survival. Am J Pathol 2004; 164:501-10.

33 Grabowski P, Kuhnel T, Muhr-Wilkenshoff F, et al. Prognostic value of nuclear survivin expression in oesophageal squamous cell carcinoma. Br J Cancer 2003; 88:115-9.

34 Moon WS, Tarnawski AS. Nuclear translocation of survivin in hepatocellular carcinoma: a key to cancer cell growth? Hum Pathol 2003; 34:1119-26.

35 Akiyama M, Hideshima T, Hayashi T, et al. Nuclear factor-êB P65 mediates tumor necrosis factor á-induced nuclear translocation of telomerase reverse transcriptase protein. Cancer Res 2003; 63:18-21.

36 Rickinson AB. Epstein-Barr Virus in Action in Vivo. N Engl J Med. 1998; 338:1461-3.

37 Chandele A, Prasad V, Jagtap JC, et al. Upregulation of survivin in $\mathrm{G} 2 / \mathrm{M}$ cells and inhibition of caspase 9 activity enhances resistance in staurosporine-induced apoptosis. Neoplasia 2004; 6: 29-40.

38 Johnson AL, Langer JS, Bridgham JT. Survivin as a cell cyclerelated and antiapoptotic protein in granulosa cells. Endocrinology 2002; 143:3405-13.

39 Rodriguez JA, Span SW, Ferreira CG, et al. CRM1-mediated nuclear export determines the cytoplasmic localization of the antiapoptotic protein Survivin. Exp Cell Res. 2002; 275: 44-53.

Edited by Zhong Cheng ZHENG 